\title{
Glutathione S-transferase M1 polymorphism and primary open-angle glaucoma (POAG) in a Chinese population.
}

\author{
Jiyun Gao ${ }^{1,2}$, Dabo Wang ${ }^{*}$, Peng Liu², Xiaojing Pan ${ }^{3}$, Teng Sun ${ }^{3}$ \\ ${ }^{1}$ Qingdao University, Qingdao, Shandong, China \\ ${ }^{2}$ Department of Ophthalmology, the Second People's Hospital of Huangdao District, Qingdao, Shandong, PR China \\ ${ }^{3}$ Department of Ophthalmology, the Affiliated Hospital Of Qingdao University, Qingdao, Shandong, PR China
}

\begin{abstract}
Primary Open-Angle Glaucoma (POAG) is a leading cause of irreversible blinding disease. We conducted this case-control study to assess the association between GSTM1 null polymorphism and POAG risk in Chinese. Unrelated 323 adult-onset POAG patients and 295 control subjects were recruited. We found that patients carrying the GSTM1 null genotype had increased risk of POAG $(\mathrm{OR}=\mathbf{1 . 8 0}, \mathbf{9 5 \%} \mathrm{CI} \mathbf{1 . 2 5 - 2 . 5 4}, \mathrm{P}=\mathbf{0 . 0 0 2})$. No statistically significantly association was found between GSTM1 polymorphism and smoking status. However, GSTM1 polymorphism was significantly associated with diabetes mellitus in patients. In conclusion, the GSTM1 polymorphism was significantly associated with the risk of POAG.
\end{abstract}

Keywords: Primary open-angle glaucoma, GSTM1D.

Accepted on October 26, 2017

\section{Introduction}

Primary Open-Angle Glaucoma (POAG) is a leading cause of irreversible blinding disease [1]. Blindness caused by glaucoma affects 8.4 million people nowadays, and this number is estimated to rise up to 11 million people for the year 2020 [2]. Current treatments are aimed at lowering Intraocular Pressure (IOP) with the goal of slowing or halting the progression of POAG.

Glutathione S Transferases (GSTs) have an essential role in protection of DNA from genotoxic damage by inhibiting the formation of DNA adducts [3]. Glutathione S-transferase M1 (GSTM1) is one of a family of proteins catalysing the conjugation of reduced glutathione to a variety of electrophilic compounds, including metabolites of benzo(a)pyrene (B(a)P) [4]. Lavaris et al. suggested that GSTM1 null genotype might be associated with increased risk of development of POAG in the Greek population [5]. Malik et al. found that GSTM1 polymorphism was not associated with JOAG risk in North Indian population [6]. Rocha et al. demonstrated that GSTM1 null polymorphism is associated with POAG in the Brazilian population [7]. However, the association between GSTM1 null polymorphism and POAG risk in Chinese is not very clear. Thus, we conducted this case-control study.

\section{Methods}

\section{Study population}

Unrelated 323 adult-onset POAG patients and 295 control subjects were recruited. All subjects were given written informed consents. The research protocol was approved by the Ethics Committee of The Affiliated Hospital of Qingdao University. Diagnosis of POAG was based on exclusion of congenital glaucoma and secondary causes (pseudoexfoliation syndrome, uveitis, trauma, steroid-induced glaucoma), anterior chamber angle open, grade III or IV gonioscopy, optic nerve and visual field changes compatible with glaucomatous damage, and initial IOP (before treatment) above $21 \mathrm{mmHg}$.

\section{DNA extraction and genotyping}

DNA was isolated from peripheral blood samples by standard methods. The polymorphism of the GSTM1 loci arises from the complete deletion. DNA was amplified in a total volume of $20 \mu$ containing $10 \mathrm{pmol}$ of each primer, 0.5 unit of Taq DNA polymerase, $1.5 \mathrm{mM} \mathrm{MgCl} 2$ and PCR buffer. Following an initial denaturation step at $94^{\circ} \mathrm{C}$ for $3 \mathrm{~min}, 35$ cycles of amplification were carried out at $94^{\circ} \mathrm{C}$ for $45 \mathrm{~s}, 60^{\circ} \mathrm{C}$ for $45 \mathrm{~s}$ and $72^{\circ} \mathrm{C}$ for $45 \mathrm{~s}$. Both positive and negative controls were analysed in each experiment. GSTM1 genotypes were not scored unless the PCR product from the internal reference $\beta$ globulin was evident. 


\section{Statistical analysis}

$\chi^{2}$ tests were used to examine the differences in the distributions of genotypes between cases and controls. The association between the GSTM1 polymorphism and risk of POAG was estimated by Odds Ratios (ORs) and their 95\% Confidence Intervals (CIs), which were calculated by unconditional logistic regression. Statistical analyses were carried out using the SPSS WIN v 16.0 statistical package (SPSS, Chicago, IL).

\section{Results}

Relevant characteristics of the study subjects are given in Table 1. The distributions for gender and age among cases and controls were not statistically different. The median age was 62 $\mathrm{y}$ for cases and $61 \mathrm{y}$ for controls. The distribution of smokers was higher in cases than in controls. The distribution of diabetes mellitus was not different between cases and controls.

The OR and $95 \%$ CI for the GSTM1 polymorphism and the risk of POAG were shown in Table 2. We found that patients carrying the GSTM1 null genotype had increased risk of POAG (OR=1.80, 95\% CI 1.25-2.54, $\mathrm{P}=0.002)$. The results in Table 3 suggested no statistically significantly association between GSTM1 polymorphism and smoking status. However, GSTM1 polymorphism was significantly associated with diabetes mellitus in patients.

Table 1. Clinical characteristics of the patients.

\begin{tabular}{lll}
\hline Characteristics & Number of patients $(\mathbf{n}=\mathbf{3 2 3})$ & $\begin{array}{l}\text { Number } \\
(\mathbf{n}=\mathbf{2 9 5})\end{array}$ \\
\hline Age $(\mathrm{y})$ & & of \\
\hline Median & $62 \pm 9.10$ & $61 \pm 9.29$ \\
\hline Gender & 196 & 198 \\
\hline Men & 127 & 97 \\
\hline Women & & \\
\hline Smoking status & & 49 \\
\hline Current smokers & 105 & 246 \\
\hline No-smokers & 218 & \\
\hline Diabetes mellitus & & 24 \\
\hline Yes & 70 & 271 \\
\hline No & 253 &
\end{tabular}

Table 2. Association between GSTM1 polymorphism and POAG risk.

\begin{tabular}{lllll}
\hline & Case & Control & OR $(95 \%$ Cl) & P value \\
\hline GSTM1 present & 219 & 233 & 1 (Reference) & \\
\hline GSTM1 null & 104 & 62 & $1.80(1.25-2.54)$ & 0.002 \\
\hline
\end{tabular}

Table 3. Association between characteristics and GSTM1 polymorphism.

\begin{tabular}{lllll}
\hline Characteristics & GSTM1 present & GSTM1 null & OR $(95 \% \mathrm{CI})$ & P value \\
\hline Smoking status & & & & \\
\hline Current smokers & 67 & 37 & 1 (Reference) & \\
\hline No-smokers & 152 & 67 & $0.61(0.31-1.23)$ & 0.16 \\
\hline Diabetes mellitus & & & & \\
\hline Yes & 21 & 49 & 1 (Reference) & \\
\hline No & 198 & 55 & $0.43(0.22-0.67)$ & 0.001 \\
\hline
\end{tabular}

\section{Discussion}

In our study, we investigated whether GSTM1 polymorphism could have an impact on risk for developing POAG in the Chinese population. We found that patients carrying the GSTM1 null genotype had increased risk of POAG.

Juronen et al. suggests that the GSTM1 polymorphism may be associated with increased risk of development of primary openangle glaucoma [8]. However, Jansson et al. found no evidence of association between GSTM1 and glaucoma in the Swedish population [9]. Fan et al. suggested that variants in TNF and TP53 are risk factors for POAG [10]. Huang et al. found that dual null genotype of GSTM1/GSTT1 is associated with increased risk of POAG [11]. Safa et al. found that increased frequencies of GSTM1 null in patients with PCAG could be a risk factor for incidence of PCAG in the Iranian population [12].

This study has several limitations. First, we only measured the GSTM1 polymorphism. Second, the presence of other factor may have biased the control group in this study. Finally, the sample size of the study was relatively small, and a larger number of subjects are needed to properly evaluate their characteristics.

In conclusion, the GSTM1 polymorphism was significantly associated with the risk of POAG.

\section{Conflicts of Interest}

None

\section{References}

1. Flammer J, Mozaffarieh M. What is the present pathogenetic concept of glaucomatous optic neuropathy? Sur Ophthalmol 2007; 52: 162-173.

2. Quigley HA, Broman AT. The number of people with glaucoma worldwide in 2010 and 2020. Br J Ophthalmol 2006; 90: 262-267.

3. Ryberg D, Skaug V, Hewer A, Phillips DH, Harries LW, Wolf CR, Ogreid D, Ulvik A, Vu P, Haugen A. Genotypes of glutathione transferase $\mathrm{M} 1$ and $\mathrm{P} 1$ and their significance for lung DNA adduct levels and cancer risk. Carcinogenesis 1997; 18: 1285-1289.

4. Minina VI, Soboleva OA, Glushkov AN, Voronina EN, Sokolova EA, Bakanova ML, Savchenko YA, Ryzhkova AV, Titov RA, Druzhinin VG, Sinitsky MY, Asanov MA. 
Polymorphisms of GSTM1, GSTT1, GSTP1 genes and chromosomal aberrations in lung cancer patients. J Cancer Res Clin Oncol 2017.

5. Lavaris A, Gazouli M, Brouzas D, Moschos MM. Polymorphism analysis of GSTM1 and OPA1 genes in Greek patients with primary open-angle glaucoma. In Vivo 2016; 30: 473-477.

6. Malik MA, Gupta V, Shukla S, Kaur J. Glutathione Stransferase (GSTM1, GSTT1) polymorphisms and JOAG susceptibility: a case control study and meta-analysis in glaucoma. Gene 2017; 628: 246-252.

7. Rocha AV, Talbot T, Magalhaes da Silva T, Almeida MC, Menezes CA, Di Pietro G, Rios-Santos F. Is the GSTM1 null polymorphism a risk factor in primary open angle glaucoma? Mol Vis 2011; 17: 1679-1686.

8. Juronen E, Tasa G, Veromann S, Parts L, Tiidla A, Pulges R, Panov A, Soovere L, Koka K, Mikelsaar AV. Polymorphic glutathione S-transferase M1 is a risk factor of primary open-angle glaucoma among Estonians. Exp Eye Res 2000; 71: 447-452.

9. Jansson M, Rada A, Tomic L, Larsson LI, Wadelius C. Analysis of the glutathione S-transferase M1 gene using pyrosequencing and multiplex PCR-no evidence of association to glaucoma. Exp Eye Res 2003; 77: 239-243.

10. Fan BJ, Liu K, Wang DY, Tham CC, Tam PO. Association of polymorphisms of tumor necrosis factor and tumor protein p53 with primary open-angle glaucoma. Invest Ophthalmol Vis Sci 2010; 51: 4110-4116.

11. Huang W, Wang W, Zhou M, Chen S, Zhang X. Association of glutathione S-transferase polymorphisms (GSTM1 and GSTT1) with primary open-angle glaucoma: an evidence-based meta-analysis. Gene 2013; 526: 80-86.

12. Safa FK, Shahsavari G, Abyaneh RZ. Glutathione stransferase M1 and T1 genetic polymorphisms in Iranian patients with glaucoma. Iran J Basic Med Sci 2014; 17: 332-336.

\section{*Correspondence to}

Dabo Wang

Department of Ophthalmology

The Affiliated Hospital of Qingdao University

PR China 